
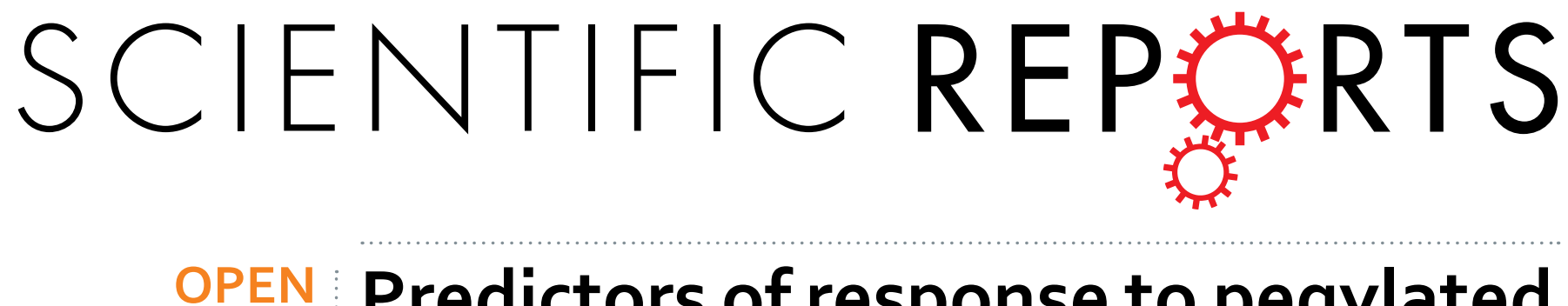

\title{
Predictors of response to pegylated interferon in chronic hepatitis B: a real-world hospital-based analysis
}

Received: 22 January 2016

Accepted: 22 June 2016

Published: 12 July 2016

\author{
Yin-Chen Wang ${ }^{1}$, Sien-Sing Yang ${ }^{2}$, Chien-Wei Su ${ }^{1}$, Yuan-Jen Wang ${ }^{3}$, Kuei-Chuan Lee ${ }^{1}$, \\ Teh-la Huo ${ }^{1,4}$, Han-Chieh Lin ${ }^{1}$ \& Yi-Hsiang Huang ${ }^{1,5}$
}

Information on the efficacy of pegylated interferon (PEG-IFN) treatment of chronic hepatitis B (CHB) patients and predictors of the response based on real-world data is limited. Consecutive 201 patients who underwent PEG-IFN treatment for CHB were reviewed. A virological response (VR) was defined as a serum HBV DNA of $<2000 \mathrm{IU} / \mathrm{mL}$, and a combined response (CR) was defined a VR accompanied by serological response for hepatitis $\mathrm{B}$ e antigen (HBeAg)-positive $\mathrm{CHB}$. For HBeAg-positive CHB patients, the $\mathrm{HBeAg}$ seroconversion rate and $\mathrm{CR}$ rate were $30.5 \%$ and $21.2 \%$ at 48 weeks after end of treatment (EOT), respectively. Baseline alanine aminotransferase (ALT) level was associated with $\mathrm{HBeAg}$ seroconversion, while baseline hepatitis $B$ s antigen (HBsAg) levels of $<250 \mathrm{IU} / \mathrm{mL}$ and $\mathrm{HBV}$ DNA $<2.5 \times 10^{7} \mathrm{IU} / \mathrm{mL}$ were strongly associated with sustained off-treatment $\mathrm{CR}$. For $\mathrm{HBeAg}$-negative $\mathrm{CHB}$, the VR rates were $85.5 \%$, and $27.7 \%$ at EOT, and 48 weeks after EOT, respectively; a baseline $\mathrm{HBsAg}$ $<1,250 \mathrm{IU} / \mathrm{mL}$ was associated with sustained off-treatment VR. PEG-IFN treatment has durable $\mathrm{HBeAg}$ seroconversion in $\mathrm{HBeAg}$-positive $\mathrm{CHB}$, but results in a high risk of relapse among $\mathrm{HBeAg}$-negative $\mathrm{CHB}$ patients. Pre-treatment HBsAg level is an important predictor of VR in CHB patients undergoing PEGIFN treatment.

Hepatitis B virus (HBV) infection is a global health issue. Approximately, 248 million people are chronic carriers of the HBV across the world ${ }^{1}$. Chronic HBV infection may result in the development of serious complications, such as liver cirrhosis and hepatocellular carcinoma (HCC). Although a hepatitis B vaccine has been available for more than two decades, there is still between $5 \%$ and $10 \%$ of the adult population chronically infected with $\mathrm{HBV}$ in $\mathrm{Asia}^{2,3}$.

The treatment options for chronic hepatitis B include nucleoside or nucleotide analogues (NUCs), and interferon (IFN) or pegylated interferon (PEG-IFN) based on current treatment guidelines ${ }^{4-6}$. NUCs are able to effectively suppress the HBV viral loads and reduce liver-related morbidity and mortality ${ }^{7-9}$. However, the virological and clinical relapse rates are high after cessation of the treatment; therefore long-term treatment is usually required $^{10}$. In contrast, PEG-IFN has the advantage of a finite course treatment duration without the possibility of drug resistance. Nevertheless, the response rate of PEG-IFN is not satisfactory based on previous clinical trials $^{11-13}$. Due to the more frequent adverse effects and the route of administration, only limited numbers of CHB patients have received PEG-IFN treatment in clinical practice, consequently, real-world data on the response to PEG-IFN among CHB patients has rarely been reported.

Several prediction factors are known to be associated with treatment response among PEG-IFN treated patients based on previous clinical trials. In HBeAg-positive CHB patients, a high alanine aminotransferase (ALT) level, a low HBV viral load at baseline, genotype A HBV, and a decline in serum HBsAg level during the treatment have been associated with a clinical response in previous studies ${ }^{14-17}$. Among HBeAg-negative CHB patients, very few baseline predictors have been proposed and a response-guided treatment according to serial HBsAg decline is recommended ${ }^{18-23}$. Nevertheless, predictors of PEG-IFN treatment among CHB patients based on real-world data remains in an unmet need.

${ }^{1}$ Division of Gastroenterology and Hepatology, Department of Medicine, Taipei Veterans General Hospital, Taipei, Taiwan. ${ }^{2}$ Liver Center, Cathay General Hospital Medical Center, Taipei, Taiwan. ${ }^{3}$ Health Care Center, Taipei Veterans General Hospital, Taipei, Taiwan. ${ }^{4}$ Institute of Pharmacology, National Yang-Ming University School of Medicine, Taipei, Taiwan. ${ }^{5}$ Institute of Clinical Medicine, National Yang-Ming University School of Medicine, Taipei, Taiwan. Correspondence and requests for materials should be addressed to S.-S.Y. (email: yangss@seed.net.tw) orY.-H.H. (email:yhhuang@vghtpe.gov.tw) 
The aim of this study was to analyze the factors associated with a sustained off-treatment response to PEG-IFN $\alpha 2$ a based treatment using a real-world cohort of CHB patients from two medical centers in Taiwan, and to develop a model for identifying patients who have the best chance of responding to PEG-IFN treatment in clinical practice.

\section{Patients and Methods}

Patients. Consecutive CHB patients who underwent and completed PEG-IFN $\alpha 2$ a treatment from 2005 to 2013 were retrospectively reviewed from Taipei Veterans General Hospital and Cathay General Hospital. The inclusion criteria were age $\geq 20$ years old, positive for hepatitis B surface antigen (HBsAg) for more than 6 months before the treatment with either a positive or negative status for $\mathrm{HBeAg}$, a pretreatment serum alanine aminotransferase (ALT) equal to or more than 2 times the upper limit of normal (ULN), a baseline HBV viral load of $\geq 20,000 \mathrm{IU} / \mathrm{mL}$ for $\mathrm{HBeAg}$-positive cases and of $\geq 2,000 \mathrm{IU} / \mathrm{mL}$ for HBeAg-negative cases. The exclusion criteria included hepatitis $\mathrm{C}$ or hepatitis $\mathrm{D}$ virus co-infection, associated hepatitis related to autoimmune disease or alcohol, the patient having cirrhosis or HCC at baseline, incomplete medical records regarding the treatment response at EOT and 48 weeks after EOT, and a treatment course of less than 3 months due to intolerance or adverse events. This study was approved by Institutional Review Board Taipei Veterans General Hospital, and Institutional Review Board of the Cathay General Hospital. As a retrospective cohort data, patient informed consent was waived by both Institutional Review Boards.

PEG-IFN treatment duration and definition of responses to therapy. Based on the regulations of Taiwan National Health Insurance (NHI), adult CHB patients were eligible for PEG-IFN treatment when fulfilling the following criteria: (1) positive for HBsAg for at least 6 months (2) for HBeAg-positive patients, elevation of serum ALT levels to at least two times that of the ULN, combined with a HBV DNA level of $\geq 20,000 \mathrm{IU} / \mathrm{mL}$, and no liver decompensation; these cases are able to receive 24 weeks PEG-IFN treatment; (3) for HBeAg-negative patients, elevation of serum ALT levels to two times that of the ULN at least twice and at least 3 months interval apart, combined with a HBV viral load of $\geq 2,000 \mathrm{IU} / \mathrm{mL}$; these cases are able to receive 48 weeks of Peg-IFN treatment.

Patients received PEG-IFN $\propto 2$ a $180 \mu$ g once weekly for 24 or 48 weeks for HBeAg-positive and HBeAg-negative CHB, respectively, and the dosage was adjusted according to any adverse effect identified by their physician. The primary outcome was a sustained off-treatment virological response (VR) as defined by the EASL treatment guideline (serum HBV DNA of $<2000 \mathrm{IU} / \mathrm{mL}$ at 48 weeks post-treatment) for all CHB patients; and a serological response (HBeAg seroconversion) for $\mathrm{HBeAg}$-positive $\mathrm{CHB}$ patients ${ }^{24}$. A combined response (CR) was defined as both a serological response and a VR for HBeAg-positive patients. Responses after EOT were defined as delayed response. The secondary outcome was the relapse rate. Relapse was defined as a HBV viral rebound to higher than $2000 \mathrm{IU} / \mathrm{mL}$ among the virological responders or e seroreversion among the serological responders who were HBeAg-positive CHB patients.

Serological and biochemical assays. Routine complete blood counts and biochemical tests were performed using a systemic multi-autoanalyzer (Technicon SMAC, Technicon Instruments Corp., Tarrytown, NY) at baseline and monthly during therapy. The serum HBeAg and anti-HBe antibody levels were measured by radio-immunoassay (Abott Laboratories, North Chicago, IL). HBsAg was quantified by Elecsys HBsAg II assay (Roche Diagnostics GmbH, Mannheim, Germany). HBV viral load was determined by a PCR-based method, namely the Roche Cobas Taqman HBV DNA assay (detection limit of $12 \mathrm{IU} / \mathrm{mL}$, Roche Diagnostics, Switzerland).

Statistical analysis. Patients were categorized via a number of different approaches. Pearson chi-square analysis or Fisher exact test was used to compare categorical variables, while the Student $t$ test or Mann-Whitney $\mathrm{U}$ test was used to compare continuous variables. The associations between parameters at baseline, on-treatment, and post-treatment with response were examined by logistic regression analyses. Variables in each period with $p<0.1$ were further analyzed using a multivariate logistic regression model to identify independent variables that predicted a response. The models were developed to predict sustained off treatment responses based on the univariate and multivariate analyses. Odds ratios (OR) were convert to integer scores and the score might be adjusted according to the $\mathrm{p}$ value. All statistical analyses were performed using the Statistical Package for Social Sciences (SPSS 17.0 for Windows, SPSS Inc, Chicago, IL). A 2 -tailed $p$ value $<0.05$ was considered significant.

\section{Results}

Characteristics of the patients. A total of $222 \mathrm{CHB}$ patients (126 HBeAg-positive, $96 \mathrm{HBeAg}$-negative) were reviewed from 2005 to 2013. By exclusion criteria, $201 \mathrm{CHB}$ patients (118 HBeAg-positive, $83 \mathrm{HBeAg}$ negative) were enrolled (Table 1). HBeAg-positive $\mathrm{CHB}$ patients were significantly younger, and had higher HBV DNA levels and a higher proportion with high HBV viral loads $\left(\geq 2.5 \times 10^{7} \mathrm{IU} / \mathrm{mL}\right)$. There were no differences in gender, baseline ALT level, and HBsAg level between the two groups.

Serological, virological and combined responses. Among the $118 \mathrm{HBeAg}$-positive CHB patients, HBeAg seroconversion rates were 19.5\% $(n=23)$ and 30.5\% $(n=36)$ at EOT and 48 weeks after EOT (Fig. 1A). The ALT normalization rates were $38 \%(n=45)$ and $45 \%(n=53)$; and the combined response rates were $11 \%$ $(\mathrm{n}=13)$ and $21.2 \%(\mathrm{n}=25)$ at EOT and 48 weeks after EOT, respectively (Fig. 1B). The median HBV DNA reduction at EOT and 48 weeks post EOT were both $-2.6 \log \mathrm{IU} / \mathrm{mL}$ as compared with the baseline levels.

Among the $83 \mathrm{HBeAg-negative} \mathrm{patients,} \mathrm{the} \mathrm{virological} \mathrm{response} \mathrm{rates} \mathrm{were} 85.5 \%(n=71)$ and $27.7 \%(n=23)$ (Fig. 1C) and the ALT normalization rate were $45 \%(\mathrm{n}=37)$ and $49 \%(\mathrm{n}=41)$ at EOT and 48 weeks after EOT, respectively. The HBV DNA undetectable rates (HBV DNA $<12 \mathrm{IU} / \mathrm{mL})$ were $55.4 \%(\mathrm{n}=46)$, and $13.3 \%(\mathrm{n}=11)$ 


\begin{tabular}{|l|c|c|c|}
\hline \multirow{2}{*}{} & HBeAg-positive & HBeAg-negative & \multirow{2}{*}{} \\
\cline { 2 - 3 } & $\mathbf{N}=\mathbf{1 1 8}$ & $\mathbf{N}=\mathbf{8 3}$ & $<$ \\
\hline Age (y.) & $37.9 \pm 9.2$ & $46.4 \pm 9.7$ & $<0.001$ \\
\hline Male (\%) & $84(71 \%)$ & $67(89 \%)$ & 0.124 \\
\hline ALT (U/L) & $222.4 \pm 212.8$ & $188.6 \pm 177.5$ & 0.237 \\
\hline AST (U/L) & $110.6 \pm 108.6$ & $98.7 \pm 91.8$ & 0.334 \\
\hline Platelets $\left(\mathrm{x} 10^{3} / \mathrm{mm}^{3}\right)$ & $196.4 \pm 46.8$ & $180.8 \pm 65$ & 0.069 \\
\hline HBsAg $(\mathrm{IU} / \mathrm{mL})^{*}$ & $1702(46 \sim 291588)$ & $1991(34 \sim 50762)$ & 0.113 \\
\hline HBV DNA $(\log \mathrm{IU} / \mathrm{mL})$ & $7 \pm 1.4$ & $5.6 \pm 1.5$ & $<0.001$ \\
\hline HBV DNA $\geq 2.5 \times 10^{7} \mathrm{IU} / \mathrm{mL}(\%)$ & $59(50 \%)$ & $11(13 \%)$ & $<0.001$ \\
\hline Treatment duration $($ weeks) & $26.7 \pm 9$ & $48.1 \pm 1.8$ & $<0.001$ \\
\hline Treatment naïve $(\%)$ & $84(71.2 \%)$ & $59(71.1 \%)$ & 0.987 \\
\hline Off-treatment follow-up period (y.) & $2.36 \pm 1.14$ & $2.04 \pm 1.13$ & 0.054 \\
\hline
\end{tabular}

Table 1. Baseline characteristics of the 201 chronic hepatitis $B$ patients undergoing PEG-IFN treatment. ALT, alanine aminotransferase; HBsAg, hepatitis B surface antigen; HBV, hepatitis B virus Continuous variables are expressed as the mean \pm standard deviation or median (range). *One hundred and three HBeAg-positive and sixty $\mathrm{HBeAg}$-negative $\mathrm{CHB}$ patients had a baseline qHBsAg level.
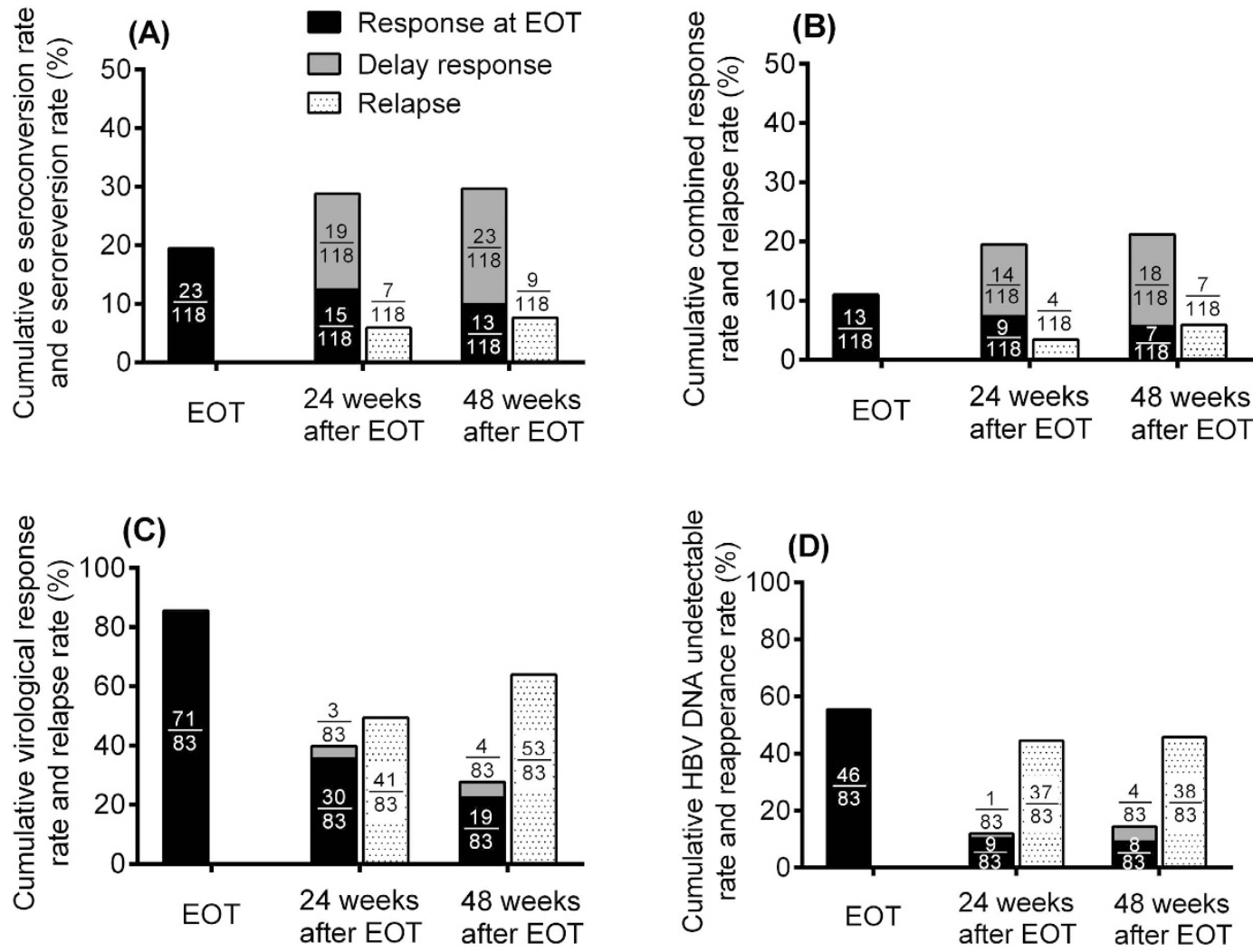

Figure 1. Off-treatment responses among $\mathrm{HBeAg}$-positive and $\mathrm{HBeAg}$-negative chronic hepatitis $\mathrm{B}$ patients. (A) Cumulative $\mathrm{HBe}$ seroconversion rate and $\mathrm{HBe}$ seroreversion rate among $\mathrm{HBeAg}$-positive $\mathrm{CHB}$ patients; (B) Cumulative combined response rate and relapse rate among HBeAg-positive CHB patients; (C) Cumulative virological response rate and relapse rate among $\mathrm{HBeAg}$-negative $\mathrm{CHB}$ patients; (D) Cumulative HBV DNA undetectable rate and relapse rate among $\mathrm{HBeAg}$-negative $\mathrm{CHB}$ patients $(\mathrm{CHB}$, chronic hepatitis B; HBV, hepatitis B virus; EOT, End of treatment). *The black bar means patients who had already achieved response [either HBeAg seroconversion (Fig. 1A), CR (Fig. 1B), VR (Fig. 1C) or HBV viral load undetectable (Fig. 1D)] at EOT. The "delay response" (grey bar) indicated patients achieving response [either HBeAg seroconversion (Fig. 1A), CR (Fig. 1B), VR (Fig. 1C) or HBV viral load undetectable (Fig. 1D)] after EOT.

at EOT, and 48 weeks after EOT, respectively (Fig. 1D). The median reductions in HBV DNA were $-4.3 \log \mathrm{IU} / \mathrm{mL}$ at EOT and $-1.1 \log \mathrm{IU} / \mathrm{mL}$ at 48 weeks after EOT as compared with the baseline levels. 


\begin{tabular}{|c|c|c|c|c|c|c|c|c|}
\hline \multicolumn{9}{|c|}{ HBeAg-positive CHB patients $(\mathrm{N}=118)$} \\
\hline & \multicolumn{4}{|c|}{ HBe seroconversion ${ }^{*}$} & \multicolumn{4}{|c|}{ Combined response $^{*}$} \\
\hline & \multicolumn{2}{|c|}{ Univariate } & \multicolumn{2}{|c|}{ Multivariate } & \multicolumn{2}{|c|}{ Univariate } & \multicolumn{2}{|c|}{ Multivariate } \\
\hline & OR $(95 \% \mathrm{CI})$ & $p$ & OR $(95 \% \mathrm{CI})$ & $\mathbf{p}$ & OR $(95 \% \mathrm{CI})$ & $\mathbf{p}$ & OR $(95 \% \mathrm{CI})$ & $\mathbf{p}$ \\
\hline Age (year) & $0.96(0.92 \sim 1.01)$ & 0.158 & & NA & $0.98(0.94 \sim 1.04)$ & 0.536 & & NA \\
\hline Sex (male) $(\mathrm{n} / \mathrm{N}=84 / 118)$ & $2.18(0.85 \sim 5.61)$ & 0.105 & & NA & $0.7(0.25 \sim 1.92)$ & 0.492 & & NA \\
\hline Treatment naïve (\%) $(\mathrm{n} / \mathrm{N}=84 / 118)$ & $0.71(0.29 \sim 1.72)$ & 0.444 & & NA & $0.96(0.36 \sim 2.56)$ & 0.931 & & NA \\
\hline Treatment duration (weeks) & $0.96(0.91 \sim 1.01)$ & 0.136 & & NA & $0.93(0.85 \sim 1.02)$ & 0.115 & & NA \\
\hline ALT $\geq 200 \mathrm{U} / \mathrm{L}(\mathrm{n} / \mathrm{N}=48 / 118)$ & $2.53(1.08 \sim 5.9)$ & 0.032 & $2.46(1.04 \sim 5.86)$ & 0.042 & $3.37(1.31 \sim 8.72)$ & 0.012 & $2.44(0.95 \sim 6.25)$ & 0.063 \\
\hline HBsAg $<250 \mathrm{IU} / \mathrm{mL}(\mathrm{n} / \mathrm{N}=33 / 103)$ & $2.42(0.98 \sim 5.97)$ & 0.054 & & NA & $2.288(1 \sim 5.23)$ & 0.05 & $2.67(1.01 \sim 6.49)$ & 0.03 \\
\hline $\mathrm{HBsAg}<1,250 \mathrm{IU} / \mathrm{mL}(\mathrm{n} / \mathrm{N}=45 / 103)$ & $1.42(0.55 \sim 3.65)$ & 0.471 & & NA & $4.57(0.56 \sim 37.55)$ & 0.157 & & NA \\
\hline HBsAg $<25,000 \mathrm{IU} / \mathrm{mL}(\mathrm{n} / \mathrm{N}=93 / 103)$ & $10.45(1.34 \sim 81.6)$ & 0.025 & $\begin{array}{c}7.93 \\
(0.99 \sim 63.68)\end{array}$ & 0.051 & $6.41(0.82 \sim 50.44)$ & 0.078 & & NA \\
\hline HBV DNA $<2.5 \times 10^{7}(\mathrm{IU} / \mathrm{mL})(\mathrm{n} / \mathrm{N}=59 / 118)$ & $1.3(0.6 \sim 2.84)$ & 0.51 & & NA & $2.66(1.04 \sim 6.78)$ & 0.041 & $2.87(1.27 \sim 6.5)$ & 0.011 \\
\hline
\end{tabular}

Table 2. Univariate and multivariate analysis of baseline factors associated with 48 weeks of off-treatment $\mathrm{HBe}$ seroconversion and combined response among $\mathrm{HBeAg}$-positive chronic hepatitis $\mathrm{B}$. OR, Odds ratio; CI, confidence interval; NA, not adopted; NS, not significant; ALT, alanine aminotransferase; HBsAg, hepatitis B surface antigen; $\mathrm{HBV}$, hepatitis $\mathrm{B}$ virus. *Among $118 \mathrm{HBeAg}$-positive $\mathrm{CHB}$ patients, $\mathrm{HBeAg}$ seroconversion rate and the combined response rate were $31.4 \%(37 / 118)$ and $21.2 \%(25 / 118)$ at 48 weeks after EOT.

HBsAg loss. Within 48 weeks after EOT, only one case among the HBeAg-positive patients and two cases among the HBeAg-negative patients developed HBsAg loss and none had anti-HBs seroconversion.

Factors associated with responses in HBeAg-positive CHB patients. Baseline factors associated with the e seroconversion and the sustained off-treatment combined response among $\mathrm{HBeAg}$-positive $\mathrm{CHB}$ patients were analyzed (Table 2). By univariate analysis, the baseline ALT $\geq 200 \mathrm{IU} / \mathrm{L}$ and $\mathrm{HBsAg}<25,000 \mathrm{IU} / \mathrm{mL}$ were associated with e seroconversion among $\mathrm{HBeAg}$-positive patients. After multivariate analysis, baseline $\mathrm{ALT} \geq 200 \mathrm{IU} / \mathrm{L}$ remained associated with e seroconversion. By univariate analysis, baseline HBV DNA $<$ $2.5 \times 10^{7} \mathrm{IU} / \mathrm{mL}, \mathrm{ALT} \geq 200 \mathrm{U} / \mathrm{L}$, and $\mathrm{HBsAg}<250 \mathrm{IU} / \mathrm{mL}$ were associated with the combined response among HBeAg-positive patients. After multivariate analysis, only baseline HBV DNA of $<2.5 \times 10^{7} \mathrm{IU} / \mathrm{mL}$ and $\mathrm{HBsAg}$ level of $<250 \mathrm{IU} / \mathrm{mL}$ remained independently associated with the combined response among HBeAg-positive patients.

On-treatment HBsAg level on weeks 12 was available in $34 \mathrm{HBeAg}$-positive cases. Of them, 22 patients had at least $10 \%$ of decline compare to their pretreatment level. Genotype was available in 39 cases. Of them, 22 were genotype B, 17 were genotype C. Nether on-treatment HBsAg decline nor genotype of HBV was associated with response in the subgroup patients (Supplementary Table S1).

Models for predicting PEG-IFN treatment response in HBeAg-positive CHB patients. Based on the odds ratios and $\mathrm{p}$ value obtained from the multivariate analysis of responses among $\mathrm{HBeAg}$-positive $\mathrm{CHB}$ patients, individual scores were assigned to each factor as listed in Table 3. Model A included in HBsAg < $250 \mathrm{IU} / \mathrm{mL}$ and HBV DNA $<2.5 \times 107(\mathrm{IU} / \mathrm{mL})$. In the model $\mathrm{B}$, we further enrolled baseline ALT $\geq 200 \mathrm{U} / \mathrm{L}$ and adjusted the weighted point; because the baseline ALT $\geq 200 \mathrm{U} / \mathrm{L}$ was significant in multivariate analysis of the $\mathrm{e}$ seroconversion and univariate analysis of the combined response for HBeAg-positive $\mathrm{CHB}$ patients. According to the scores, the response rates were categorized into three groups: a low, median, and high probability of response for $\mathrm{HBeAg}$-positive patients (Fig. 2). Among HBeAg-positive patients, the sustained off-treatment combined response rate/and $\mathrm{HBe}$ seroconversion rates were $9 \%$ (3/33)/30\% (10/33), $21 \%(10 / 48) / 35 \%(17 / 48)$, and $27 \%$ $(6 / 22) / 32 \%(7 / 22)$ for the low probability group (score 0$)$, median probability group (score 1 ), and high probability group (score 2) in model A. The sustained off-treatment combined response rate/and HBe seroconversion rates were $5 \%(1 / 21) / 19 \%(4 / 21), 16 \%(9 / 55) / 27 \%(15 / 55)$, and $33 \%(9 / 27) / 41 \%(11 / 27)$ for the low probability group (score 0,1 ), median probability group (score 2,3 ), and high probability group (score 4,5$)$ in model B.

Factors associated with responses in HBeAg-negative $\mathrm{CHB}$ patients. Factors associated with a sustained off-treatment VR among $\mathrm{HBeAg}$-negative $\mathrm{CHB}$ patients were listed in Table 4 . Among the $\mathrm{HBeAg}$-negative $\mathrm{CHB}$ patients, the baseline $\mathrm{HBsAg}$ of $<1,250 \mathrm{IU} / \mathrm{mL}$, and the treatment-experienced were associated with sustained off-treatment response in univariate analysis. After multi-variate analysis, only a baseline HBsAg of $<1,250 \mathrm{IU} / \mathrm{mL}$ was the significant one. The virological response rates at 48 weeks off-treatment were $50 \%(11 / 22)$ and $10.5 \%(4 / 38)$ in HBeAg-negative CHB patients with baseline $\mathrm{HBs} A g$ of $<1,250 \mathrm{IU} / \mathrm{mL}$ and $\geq 1,250 \mathrm{IU} / \mathrm{mL}$. (Fig. 3)

On-treatment $\mathrm{HBsAg}$ on week 12 were available in $35 \mathrm{HBeAg}$-negative $\mathrm{CHB}$ patients. On-treatment $\mathrm{HBsAg}$ decline $\geq 10 \%$ (OR: $8.75, p=0.056)$ or $\geq 1 \log (\mathrm{OR}: 25.83, \mathrm{p}=0.004)$ were associated with sustained off-treatment response. Thirty-five patients had available HBV genotype data (23 genotype $\mathrm{B}$, and 12 genotype $\mathrm{C}$ ). There were no differences in response between genotype B and C patients by logistic regression analysis (Supplementary Table S2). 
(A)

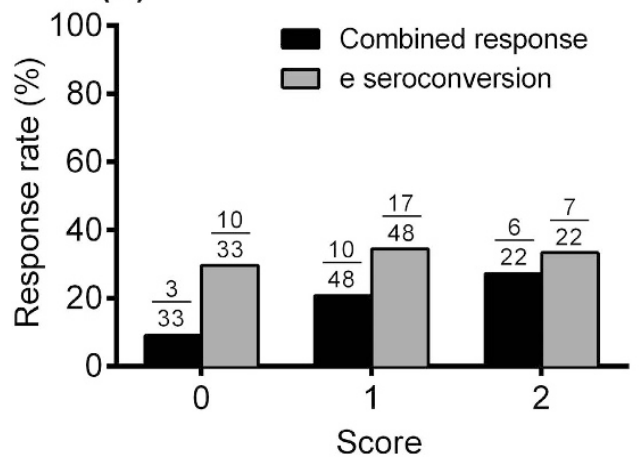

(B)

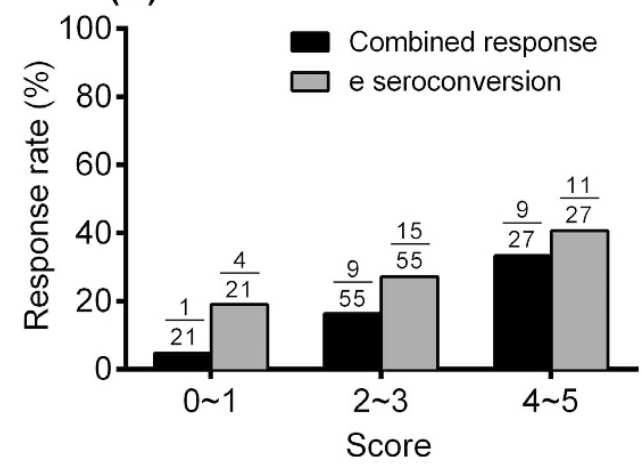

Figure 2. Response rates of models for a sustained off-treatment response at 48 weeks after end of treatment among HBeAg-positive chronic hepatitis B patients. The HBe seroconversion rate and combined response rate in $\mathrm{HBeAg}$-positive chronic hepatitis B patients with different scores according to (A) model A, and $(\mathbf{B})$ model B.

\begin{tabular}{|l|c|}
\hline \multicolumn{2}{|c|}{ HBeAg-positive CHB patients } \\
\hline Factors & points \\
\hline Model A \\
\hline HBsAg $<250 \mathrm{IU} / \mathrm{mL}$ & 1 \\
\hline HBV DNA $<2.5 \times 10^{7} \mathrm{IU} / \mathrm{mL}$ & 1 \\
\hline Model B \\
\hline HBsAg $<250 \mathrm{IU} / \mathrm{mL}$ & 2 \\
\hline HBV DNA $<2.5 \times 10^{7} \mathrm{IU} / \mathrm{mL}$ & 2 \\
\hline ALT $\geq 200 \mathrm{U} / \mathrm{L}$ & 1 \\
\hline
\end{tabular}

Table 3. Two models for predicting sustained off-treatment combined response at 48 weeks after EOT among HBeAg-positive chronic hepatitis B patients. HBsAg, hepatitis B surface antigen; HBV, hepatitis B virus; ALT, alanine aminotransferase.

\begin{tabular}{|l|c|c|c|c|}
\hline \multicolumn{2}{|c|}{ HBeAg-negative CHB patients $(\mathrm{N}=83)$} \\
\hline & \multicolumn{2}{|c|}{ Univariate } & \multicolumn{2}{c|}{ Multivariate } \\
\cline { 2 - 5 } & OR (95\% CI) & $\boldsymbol{p}$ & OR (95\% CI) & NA \\
\hline Age (year) & $0.98(0.94 \sim 1.04)$ & 0.53 & & NA \\
\hline Sex $($ male) $(\mathrm{n} / \mathrm{N}=71 / 83)$ & $0.72(0.14 \sim 3.7)$ & 0.698 & & 0.343 \\
\hline Treatment naive $(\%)(\mathrm{n} / \mathrm{N}=59 / 83)$ & $0.21(0.06 \sim 0.69)$ & 0.011 & $0.36(0.04 \sim 2.99)$ & NA \\
\hline Treatment duration $($ weeks $)$ & $0.65(0.34 \sim 1.24)$ & 0.192 & & NA \\
\hline ALT $\geq 200 \mathrm{U} / \mathrm{L}(\mathrm{n} / \mathrm{N}=23 / 83)$ & $1.2(0.42 \sim 3.46)$ & 0.732 & & NA \\
\hline HBsAg $<250 \mathrm{IU} / \mathrm{mL}(\mathrm{n} / \mathrm{N}=10 / 60)$ & $1.06(0.18 \sim 6.29)$ & 0.948 & & 0.006 \\
\hline HBsAg $<1,250 \mathrm{IU} / \mathrm{mL}(\mathrm{n} / \mathrm{N}=22 / 60)$ & $6.13(1.09 \sim 34.35)$ & 0.039 & $10.39(5.96 \sim 55.04)$ & NA \\
\hline HBV DNA $<2.5 \times 10^{7}(\mathrm{IU} / \mathrm{mL})(\mathrm{n} / \mathrm{N}=72 / 83)$ & $4.4(0.53 \sim 36.51)$ & 0.17 & & \\
\hline
\end{tabular}

Table 4. Univariate and multivariate analysis of baseline factors associated with sustained off-treatment virological response among $\mathrm{HBeAg-negative} \mathrm{chronic} \mathrm{hepatitis} \mathrm{B}$ patients ${ }^{*}$. OR, Odds ratio; $\mathrm{CI}$, confidence interval; NA, not adopted; ALT, alanine aminotransferase; HBsAg, hepatitis B surface antigen; HBV, hepatitis B virus. *Among $83 \mathrm{HBeAg-negative} \mathrm{CHB}$ patients, sustained off-treatment virological response rate was $27.7 \%$ $(23 / 83)$ at 48 weeks after EOT.

Relapse. Among all HBeAg-positive patients, only 9 (7.6\%) and 7 (5.93\%) cases developed relapse after achieving serological or combined response at EOT (Fig. 1A,B). However, 53 (63.9\%) HBeAg-negative CHB patients developed relapse at 48 weeks after EOT (Fig. 1C), and 38 cases (45.8\%) became HBV DNA detectable at 48 weeks after EOT (Fig. 1D).

Among HBeAg-negative CHB patients, baseline $\mathrm{HBsAg} \geq 1,250 \mathrm{IU} / \mathrm{mL}$ and detectable $\mathrm{HBV}$ viral load at EOT were significantly associated with relapse among responders at EOT by logistic regression analysis (Supplementary Table S3). Individual scores were assigned to each factor as listed in Supplementary Table S4. The model A included the baseline HBsAg $\geq 1,250 \mathrm{IU} / \mathrm{mL}$ and detectable HBV viral load at EOT. In subgroup of cases, 


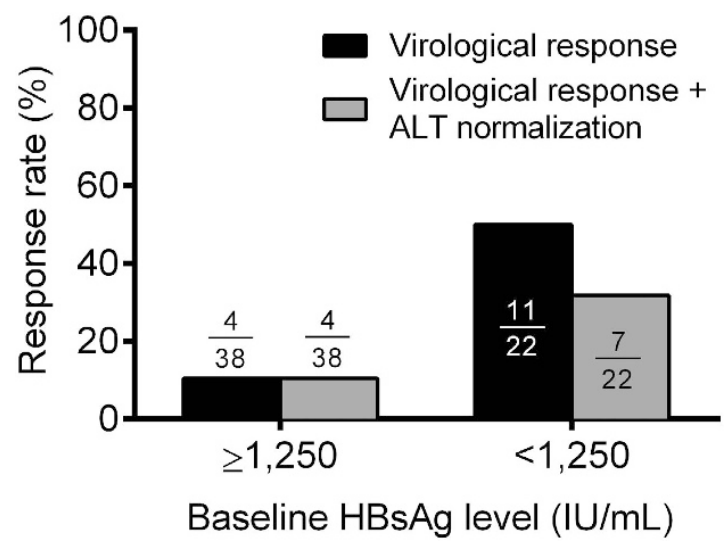

Figure 3. Response rates at 48 weeks after EOT among HBeAg-negative chronic hepatitis B patients. The response rates among $\mathrm{HBeAg}$-negative chronic hepatitis $\mathrm{B}$ patients according to baseline HBsAg levels.

on-treatment HBsAg decline $<1 \log$ and $\mathrm{HBsAg} \geq 200 \mathrm{IU} / \mathrm{mL}$ at EOT were included into model $\mathrm{B}$. According to the scores, the risk of relapse can be stratified into three groups (Supplementary Figure S1). Patients who fulfilled all factors in each model had the highest risk of relapse.

\section{Discussions}

PEG-IFN is one of the main standard treatments for CHB, however, the efficacy of PEG-IFN, based on real-world data, has rarely been reported. PEG-IFN showed durable e seroconversion in HBeAg-positive CHB in our real-world data. Only few patients experienced HBeAg seroreversion, and an additional $20 \%$ of the patients would achieve delayed e seroconversion after completing the treatment. In the phase II and III studies of PEG-IFN, the HBeAg seroconversion rate was equivalent by 24 or 48 weeks of the treatment ${ }^{13,25}$. Therefore, 24 weeks of PEG-IFN remains the standard of care for HBeAg-positive CHB in Taiwan; even though 48 weeks of PEG-IFN treatment has been shown to provide a better e seroconversion rate than 24 weeks of treatment $(36.2 \%$ vs. $22.9 \%$ at 6 months after EOT) ${ }^{11}$. The HBeAg seroconversion rate of $31.4 \%$ in our HBeAg-positive patients was similar to the report of the phase III study. The long-term effect of PEG-IFN is durable for HBeAg-positive CHB in our finding which complies with previous findings ${ }^{11,13,26}$.

A low HBV viral load and a high ALT level at baseline were associated with serological response of IFN treatment. ${ }^{14,27-29}$ Recently, on-treatment HBsAg decline is considered to be an important factor associated with the response to PEG-IFN in both $\mathrm{HBeAg}$-positive and $\mathrm{HBeAg}$-negative $\mathrm{CHB}^{18,19,21,30}$. An on-treatment $\mathrm{HBsAg}$ level of $<1,500 \mathrm{IU} / \mathrm{mL}$ at weeks 12 or 24 was strongly associated with immune control in $\mathrm{HBeAg}$-positive $\mathrm{CHB}^{17,31}$. HBsAg production is associated with HBV replication and the level of intrahepatic cccDNA ${ }^{32}$, but only few studies proposed the importance of pretreatment HBsAg level to predict PEG-IFN response ${ }^{20,33}$. HBsAg level is also a predictor when switching to PEG-IFN in HBeAg-positive CHB patients under long-term NUCs treatment ${ }^{34}$. The best cut-off for the baseline HBsAg level when predicting the combined response in HBeAg-positive CHB has not been well-established in the past. In our study, a baseline HBsAg level of $<250 \mathrm{IU} / \mathrm{mL}$ had the highest sustained off-treatment CR rate of $30.3 \%$. The limitation was that only $32 \%(33 / 103)$ of HBeAg-positive patients met this criterion. Among patients whose baseline HBsAg levels were between $250 \mathrm{IU} / \mathrm{mL}$ to $1,250 \mathrm{IU} / \mathrm{mL}$, the sustained CR rate was 25\%; and among patients with a high baseline $\mathrm{HBsAg}(\geq 1,250 \mathrm{IU} / \mathrm{mL})$, the sustained CR rate was only $14.3 \%$. Among the patients with available on-treatment HBsAg data in HBeAg-positive CHB patients, only few cases had achieved HBsAg decline and there was no effect on the response.

Previous studies have produced several models for predicting the response to PEG-IFN among HBeAg-positive CHB patients. Buster et al. ${ }^{14}$ suggests genotypes B and C patients who have high ALT levels and low HBV viral loads at baseline are likely to have the highest sustained response to PEG-IFN among HBeAg-positive CHB. A scoring model based on a HBV viral load of $<2.5 \times 10^{7} \mathrm{IU} / \mathrm{mL}$, a HBsAg level of $<250 \mathrm{IU} / \mathrm{mL}$, with or without an ALT $\geq 200 \mathrm{U} / \mathrm{L}$, was established to predict the response to PEG-IFN among HBeAg-positive CHB. This model has a number of advantages. Firstly, all of the parameters are baseline factors and thus can be applied before treatment begins. Secondly, these parameters are easily accessible in a real-world clinical situation without additional laboratory tests, except that the HBsAg quantification is not widely available in all countries.

Among HBeAg-negative patients, an extremely high VR at EOT was observed in our real-world data, but the relapse rate was also high. Marcellin et al. ${ }^{35}$ also reported that the virological response with a HBV viral load of $<20,000$ copies or $<400$ copies were $43 \%$, and $19 \%$, respectively at 6 months after 48 weeks of PEG-IFN treatment. These findings indicate that PEG-IFN is able to temporarily suppress HBV but the durability of the treatment is poor in $\mathrm{HBeAg}$-negative $\mathrm{CHB}^{22,36}$. In our study, only a baseline $\mathrm{HBs} \mathrm{Ag}<1,250 \mathrm{IU} / \mathrm{mL}$ was able to predict a sustained off-treatment VR rate of 50\% among HBeAg-negative $\mathrm{CHB}$ patients. The level of HBsAg may reflect the degree of host immune control in response to $\mathrm{HBV}$, and a lower HBsAg might have a better outcome in the natural course of $\mathrm{CHB}^{37}$. Previous studies were not able to identify definite pretreatment factors that can predict the treatment response to PEG-IFN in HBeAg-negative cases. Our previous study suggested that a baseline CXCL9 level is associated with the response to PEG-IFN ${ }^{16}$. A further study to combine baseline HBsAg of $<1250 \mathrm{IU} / \mathrm{mL}$ and a high CXCL9 level might improve the prediction rate for HBeAg-negative CHB in the future. 
On-treatment more than $10 \%$ of HBsAg decline is a sign of HBsAg loss in HBeAg-negative CHB under PFG-IFN treatment ${ }^{30}$. Our data also showed the same finding in the subgroup of $\mathrm{HBeAg-negative} \mathrm{patients} \mathrm{with} \mathrm{available}$ on-treatment HBsAg data.

The poor durability of PEG-IFN treatment when treating HBeAg-negative CHB patients is still challenging. Patients who were treatment-experienced $(17 \%$ vs. $48 \%, p=0.007)$ had significant lower risk of relapse in univariate analysis only. Compared to the treatment-naive group, the treatment-experienced group had higher proportion with a HBsAg level $<1250 \mathrm{IU} / \mathrm{mL}(33 \%$ vs. $65 \%, p=0.01)$. Baseline HBsAg level, degree of on-treatment HBsAg decline, and detectable of HBV DNA at EOT are associated with the durability of the virological response to PEG-IFN among HBeAg-negative CHB patients.

There are several limitations in this study. Firstly, as a real-world retrospective study, the HBV genotype was not available in all patients, but genotype B and C seemed not associated with VR in subgroups of patients with available data. Secondly, on-treatment HBsAg levels were not available in some patients. However, on-treatment HBsAg is not an ideal predictor to select patients who are suitable for PEG-IFN before the treatment. Thirdly, our study was based on the standard of care in Taiwan with 24 weeks of PEG-IFN for HBeAg-positive CHB. Whether the model could be applied for HBeAg-positive cases with 48 weeks of PEG-IFN treatment needs further validation. Finally, further external validation is required for our prediction model.

In conclusion, PEG-IFN treatment should be carefully applied to selected CHB patients who have the best chance of a sustained off-treatment response. Pre-treatment HBsAg level is an important predictor for both $\mathrm{HBeAg}$-positive and $\mathrm{HBeAg}$-negative $\mathrm{CHB}$ for PEG-IFN treatment.

\section{References}

1. Schweitzer, A., Horn, J., Mikolajczyk, R. T., Krause, G. \& Ott, J. J. Estimations of worldwide prevalence of chronic hepatitis B virus infection: a systematic review of data published between 1965 and 2013. Lancet (London, England), doi: 10.1016/s01406736(15)61412-x (2015).

2. Wang, F. S., Fan, J. G., Zhang, Z., Gao, B. \& Wang, H. Y. The global burden of liver disease: the major impact of China. Hepatology (Baltimore, Md.) 60, 2099-2108, doi: 10.1002/hep.27406 (2014).

3. Howell, J., Van Gemert, C., Lemoine, M., Thursz, M. \& Hellard, M. An overview of hepatitis B prevalence, prevention, and management in the Pacific Islands and Territories. J Gastroenterol Hepatol 29, 1854-1866, doi: 10.1111/jgh.12684 (2014).

4. EASL clinical practice guidelines: Management of chronic hepatitis B virus infection. Journal of hepatology 57, 167-185, doi: 10.1016/j.jhep.2012.02.010 (2012)

5. Sarin, S. K. et al. Asian-Pacific clinical practice guidelines on the management of hepatitis B: a 2015 update. Hepatology international, doi: $10.1007 /$ s12072-015-9675-4 (2015)

6. Terrault, N. A. et al. AASLD guidelines for treatment of chronic hepatitis B. Hepatology (Baltimore, Md.) 63, 261-283, doi: 10.1002/ hep.28156 (2016)

7. Papatheodoridis, G. V. et al. Outcome of hepatitis B e antigen-negative chronic hepatitis B on long-term nucleos(t)ide analog therapy starting with lamivudine. Hepatology (Baltimore, Md.) 42, 121-129, doi: 10.1002/hep.20760 (2005).

8. Marcellin, P. et al. Regression of cirrhosis during treatment with tenofovir disoproxil fumarate for chronic hepatitis B: a 5-year openlabel follow-up study. Lancet (London, England) 381, 468-475, doi: 10.1016/s0140-6736(12)61425-1 (2013).

9. Wong, G. L. et al. Entecavir treatment reduces hepatic events and deaths in chronic hepatitis B patients with liver cirrhosis. Hepatology (Baltimore, Md.) 58, 1537-1547, doi: 10.1002/hep.26301 (2013).

10. Lee, I. C. et al. Durability of Nucleos(t)ide Analogues Treatment in Patients With Chronic Hepatitis B. Medicine (Baltimore) 94, e1341, doi: 10.1097/md.0000000000001341 (2015).

11. Liaw, Y. F. et al. Shorter durations and lower doses of peginterferon alfa-2a are associated with inferior hepatitis B e antigen seroconversion rates in hepatitis B virus genotypes B or C. Hepatology (Baltimore, Md.) 54, 1591-1599, doi: 10.1002/hep.24555 (2011).

12. Liaw, Y. F. et al. Lamivudine for patients with chronic hepatitis B and advanced liver disease. The New England journal of medicine 351, 1521-1531, doi: 10.1056/NEJMoa033364 (2004).

13. Lau, G. K. et al. Peginterferon Alfa-2a, lamivudine, and the combination for HBeAg-positive chronic hepatitis B. The New England journal of medicine 352, 2682-2695, doi: 10.1056/NEJMoa043470 (2005).

14. Buster, E. H. et al. Factors that predict response of patients with hepatitis B e antigen-positive chronic hepatitis B to peginterferonalfa. Gastroenterology 137, 2002-2009, doi: 10.1053/j.gastro.2009.08.061 (2009).

15. Sonneveld, M. J., Rijckborst, V., Boucher, C. A., Hansen, B. E. \& Janssen, H. L. Prediction of sustained response to peginterferon alfa-2b for hepatitis B e antigen-positive chronic hepatitis B using on-treatment hepatitis B surface antigen decline. Hepatology (Baltimore, Md.) 52, 1251-1257, doi: 10.1002/hep.23844 (2010).

16. Lee, I. C. et al. CXCL9 associated with sustained virological response in chronic hepatitis B patients receiving peginterferon alfa-2a therapy: a pilot study. PLos One 8, e76798, doi: 10.1371/journal.pone.0076798 (2013).

17. Sonneveld, M. J. et al. Response-guided peginterferon therapy in hepatitis B e antigen-positive chronic hepatitis B using serum hepatitis B surface antigen levels. Hepatology (Baltimore, Md.) 58, 872-880, doi: 10.1002/hep.26436 (2013).

18. Brunetto, M. R. et al. Hepatitis B virus surface antigen levels: a guide to sustained response to peginterferon alfa-2a in $\mathrm{HBeAg-}$ negative chronic hepatitis B. Hepatology (Baltimore, Md.) 49, 1141-1150, doi: 10.1002/hep.22760 (2009).

19. Moucari, R. et al. Early serum HBsAg drop: a strong predictor of sustained virological response to pegylated interferon alfa-2a in HBeAg-negative patients. Hepatology (Baltimore, Md.) 49, 1151-1157, doi: 10.1002/hep.22744 (2009).

20. Tangkijvanich, P. et al. Low pretreatment serum HBsAg level and viral mutations as predictors of response to PEG-interferon alpha$2 \mathrm{~b}$ therapy in chronic hepatitis B. Journal of clinical virology : the official publication of the Pan American Society for Clinical Virology 46, 117-123, doi: 10.1016/j.jcv.2009.07.005 (2009).

21. Rijckborst, V. et al. Early on-treatment prediction of response to peginterferon alfa-2a for HBeAg-negative chronic hepatitis B using HBsAg and HBV DNA levels. Hepatology (Baltimore, Md.) 52, 454-461, doi: 10.1002/hep.23722 (2010).

22. Peng, C. Y. et al. Early serum HBsAg level as a strong predictor of sustained response to peginterferon alfa-2a in HBeAg-negative chronic hepatitis B. Alimentary pharmacology \& therapeutics 35, 458-468, doi: 10.1111/j.1365-2036.2011.04973.x (2012).

23. Goulis, I. et al. On-treatment prediction of sustained response to peginterferon alfa-2a for HBeAg-negative chronic hepatitis B patients. Liver international : official journal of the International Association for the Study of the Liver 35, 1540-1548, doi: 10.1111/ liv.12725 (2015).

24. Sokal, E. M. et al. Management of chronic hepatitis B in childhood: ESPGHAN clinical practice guidelines: consensus of an expert panel on behalf of the European Society of Pediatric Gastroenterology, Hepatology and Nutrition. Journal of hepatology 59, 814-829, doi: 10.1016/j.jhep.2013.05.016 (2013).

25. Cooksley, W. G. et al. Peginterferon alpha-2a ( $40 \mathrm{kDa})$ : an advance in the treatment of hepatitis $\mathrm{B}$ e antigen-positive chronic hepatitis B. J Viral Hepat 10, 298-305 (2003). 
26. Wong, V. W. et al. Durability of peginterferon alfa-2b treatment at 5 years in patients with hepatitis B e antigen-positive chronic hepatitis B. Hepatology (Baltimore, Md.) 51, 1945-1953, doi: 10.1002/hep.23568 (2010).

27. Perrillo, R. P. et al. A randomized, controlled trial of interferon alfa- $2 \mathrm{~b}$ alone and after prednisone withdrawal for the treatment of chronic hepatitis B. The Hepatitis Interventional Therapy Group. The New England journal of medicine 323, 295-301, doi: 10.1056/ nejm199008023230503 (1990).

28. Janssen, H. L. et al. Pegylated interferon alfa-2b alone or in combination with lamivudine for HBeAg-positive chronic hepatitis B: a randomised trial. Lancet (London, England) 365, 123-129, doi: 10.1016/s0140-6736(05)17701-0 (2005).

29. Tseng, T. C. et al. Effect of host and viral factors on hepatitis B e antigen-positive chronic hepatitis B patients receiving pegylated interferon-alpha-2a therapy. Antivir Ther 16, 629-637, doi: 10.3851/imp1841 (2011).

30. Marcellin, P. et al. Hepatitis B surface antigen levels: association with 5-year response to peginterferon alfa-2a in hepatitis B e-antigen-negative patients. Hepatology international 7, 88-97, doi: 10.1007/s12072-012-9343-x (2013).

31. Piratvisuth, T. et al. Hepatitis B surface antigen: association with sustained response to peginterferon alfa-2a in hepatitis B e antigenpositive patients. Hepatology international 7, 429-436, doi: 10.1007/s12072-011-9280-0 (2013).

32. Chan, H. L. et al. Hepatitis B surface antigen quantification: why and how to use it in 2011 - a core group report. Journal of hepatology 55,1121-1131, doi: 10.1016/j.jhep.2011.06.006 (2011).

33. Chen, G. Y. et al. Baseline HBsAg predicts response to pegylated interferon-alpha2b in HBeAg-positive chronic hepatitis B patients. World J Gastroenterol 20, 8195-8200, doi: 10.3748/wjg.v20.i25.8195 (2014).

34. Ning, Q. et al. Switching from entecavir to PegIFN alfa-2a in patients with HBeAg-positive chronic hepatitis B: a randomised openlabel trial (OSST trial). Journal of hepatology 61, 777-784, doi: 10.1016/j.jhep.2014.05.044 (2014).

35. Marcellin, P. et al. Peginterferon alfa-2a alone, lamivudine alone, and the two in combination in patients with HBeAg-negative chronic hepatitis B. The New England journal of medicine 351, 1206-1217, doi: 10.1056/NEJMoa040431 (2004).

36. Marcellin, P. et al. Sustained response of hepatitis B e antigen-negative patients 3 years after treatment with peginterferon alpha-2a. Gastroenterology 136, 2169-2179.e2161-2164, doi: 10.1053/j.gastro.2009.03.006 (2009).

37. Tseng, T. C. et al. Serum hepatitis B surface antigen levels help predict disease progression in patients with low hepatitis B virus loads. Hepatology (Baltimore, Md.) 57, 441-450, doi: 10.1002/hep.26041 (2013).

\section{Acknowledgements}

The authors thank Miss. Chieh-Ju Lee to collect the data from both hospitals. The study was supported by grants from Taipei Veterans General Hospitals (V101C-147 and V103E2-001), Taipei, Taiwan.

\section{Author Contributions}

Study concept and design: Y.-H.H. and S.-S.Y.; Acquisition of data: Y.-C.W., S.-S.Y., C.-W.S., Y.-J.W., K.-C.L., T.-I.H., H.-C.L. and Y.-H.H.; Analysis and interpretation of data: Y.-C.W. and Y.-H.H.; Drafting of the manuscript: Y.-C.W. and Y.-H.H.; Critical revision of the manuscript for important intellectual content: Y.H.H.; Statistical analysis: Y.C.W. and Y.-H.H.; Administrative, technical, or material support: Y.-H.H. and S.-S.Y.; Study supervision: H.-C.L.

\section{Additional Information}

Supplementary information accompanies this paper at http://www.nature.com/srep

Competing financial interests: The authors declare no competing financial interests.

How to cite this article: Wang, Y.-C. et al. Predictors of response to pegylated interferon in chronic hepatitis B: a real-world hospital-based analysis. Sci. Rep. 6, 29605; doi: 10.1038/srep29605 (2016).

(c) (i) This work is licensed under a Creative Commons Attribution 4.0 International License. The images or other third party material in this article are included in the article's Creative Commons license, unless indicated otherwise in the credit line; if the material is not included under the Creative Commons license, users will need to obtain permission from the license holder to reproduce the material. To view a copy of this license, visit http://creativecommons.org/licenses/by/4.0/ 